\title{
Medical Biotechnology
}

\section{Sarantuya Jav, MD, PhD}

Department of Molecular Biology and Genetics, Mongolian National University of Medical Sciences, Ulaanbaatar, Mongolia

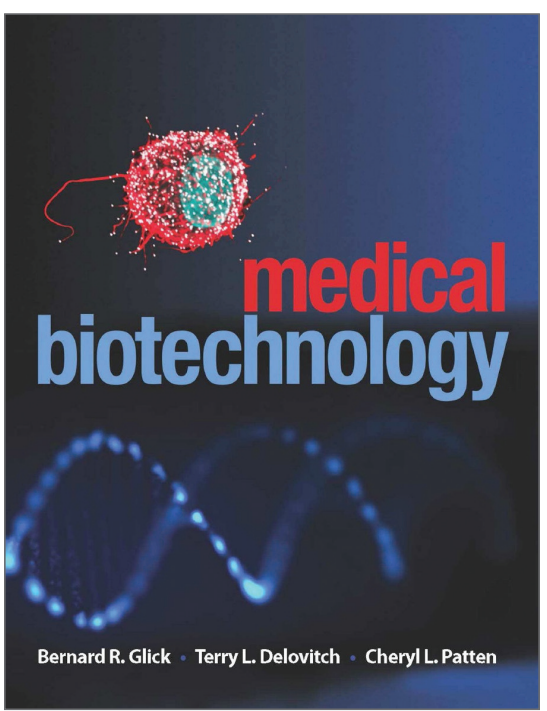

Authors: Bernard R. Glick, Terry L. Delovicitch, Cheryl L. Patten

Year: 2014

Publisher: ASM press

ISBN: $\quad 978-1-55581-705-3$

ISBN: $\quad 978-1-55581-889-0$

This is an Open Access article distributed under the terms of the Creative Commons Attribution Non-Commercial License (http://creativecommons.org/licenses/bync/4.0/) which permits unrestricted non-commercial use, distribution, and reproduction in any medium, provided the original work is properly cited. Copyright $@ 2019$ Mongolian National University of Medical Sciences
From the very beginning of the biotechnology revolution in the early 1970s, many scientists understood that this new technology would radically change the way that we think about health care. They understood early on, before any products were commercialized, that medical science was about to undergo major paradigm shift in which many of our previous assumptions and approaches would change dramatically. Forty years later, biotechnology has delivered on much of its early promise. Hundreds of new therapeutic agents, diagnostic tests, and vaccines have been delivered and are currently available in the marketplace. Moreover it is clear that we are presently just at the beginning of this revolution, with many more products in the pipeline. It is likely that, in the next 10 to 15 years, biotechnology will deliver not only new products to diagnose, prevent, and treat human disease but also entirely new approaches to treating a wide range of hither to difficult to treat or untreatable diseases.

The book Medical Biotechnology authored by Bernard R. Glick, Terry L. Delovicitch, Cheryl L. Patten holds promise as a reference and textbook for wide range of courses intended for premedical and medical students, dental students, pharmacists, optometrists, nurses, nutritionists, genetic counselors, hospital administrators, and other individual who are stakeholders in the understanding and advancement of biotechnology and its impact on the practice of modern medicine. The book is intended to be jargon free and is easy to read. In some respects, its goal to demystify the discipline of medical biotechnology. This is not a medical textbook, rather it is a discussion of the applications of many biotechniques and biochemical mechanisms can be exploited to treat selected diseases.

The book consists of main three sections: Section I explains the biology behind the technology, Section II discusses the production of therapeutic agents and Section III explores how this technology is used in diagnosing and treating human disease. Each chapter has a general scientific explanation. The first section provides understanding of fundamental technologies such as molecular cloning, amplification of DNA using PCR, DNA sequencing technologies: dideoxynucleotide procedure, pyro sequencing, sequencing using reversible 
chain terminators, sequencing by ligation, sequencing whole genomes, their strategy of handling, and more methods relating to the DNA molecule. Also, it provides specific information regarding genomics, fundamental concepts in immunology, the genetic basis of disease, immune pathogenesis, and microbial pathogenesis. The explanation of the basic concepts of immunology is well done, especially the explanation of the immune response, with a clear description of the function of cellmediated immunity, tissue and humoral immunity, the types of antibodies involved, their applications, and their immunological consequences. The genetic basis of disease is explained along with the impact of chromosomal disorders, gene mapping, gene clustering, single gene disorders, phylogenetic disorders and, and mitochondrial disorders. Immune pathogenesis is presented using models of immune system lesions, inflammation and immune hypersensitivity disorders, immunodeficiency disorders and defects in development of the immune system. The microbial pathogenesis of bacterial and viral infections is explained along with targets for treatment of them.

The second section has two chapters (6-7) that explain modulation of gene expression and genetic engineering. This includes how to manipulate the expression of genes in prokaryotes, heterologous protein production in eukaryotic cells, directed mutagenesis with M13 DNA and plasmid DNA, and also PCR-amplified oligonucleotide-directed mutagenesis.

The third section is focused on the field of diagnosing and treating human diseases and includes five chapters. There is an excellent explanation of molecular diagnostics, that includes immunological approaches to detect protein biomarkers of disease, DNA based approaches to disease diagnosis, and the detection of disease using RNA signatures. The chapter on protein therapeutics includes the subjects of pharmaceuticals, including interferon, human growth hormone, tumor necrosis factor, targeting mitochondria, extending protein half-life, engineered bacteriophages and discusses the usage of recombinant antibodies, enzymes and lactic acid bacteria. Finally, it provides an understanding of human gene therapy and vaccines, their main principles.

Thus, this book may be considered a biomedical road map that provides a fundamental understanding of the many approaches being pursued by scientists to diagnose, prevent, and treat wide range of ailments and how our current understanding of the immune system and therapies may be leveraged to create future treatments. While predicting future developments in this rapidly developing field is challenging, this volume provides a useful foundation to understand medical biotechnology for wide range of individuals. 